\title{
In Pursuit of Equity: Applying Design Thinking to Develop a Values-Based open access Statement
}

\author{
Lillian Rigling, Emily Carlisle, \& Courtney Waugh
}

\section{In Brief}

We wanted to rethink how our library supported open access, so we attempted to ask ourselves and our staff why they supported "open" and how they defined "open". By unpacking our institutional and individual understandings of "open" using design thinking principles, we were able to not only create a strong and value-driven statement, but to also open the door for staff at all levels to engage in policy-making for the organization.

\section{Introduction}

On August 2, 2017 Elsevier announced its acquisition of bepress, the academic software firm that produces Digital Commons-an institutional repository platform used by libraries across North America. At the University of Western Ontario, the largest bepress institution in Canada, the news came as a surprise to library staff. Conflicting opinions arose: our users appreciated Digital Commons' features, but to use an Elsevier product for a repository intended to disseminate open access (OA) works would run contrary to our organizational and professional values. Our professional ethos to support equitable access to scholarship and our professional ideal of user-centred decision making seemed to be in direct opposition to one another. At least, that was the conflict that we anticipated, until we realized that the individual values of Western Libraries' staff-and subsequently their individual understandings of OA-are not as homogenous as we had first assumed. As Roger C. Schonfeld (2017b) put it, we have over time failed to "align unambiguously on what [our library and its support for OA are] trying to accomplish." Without a strong foundation, we have consequently failed to create meaningful strategic avenues within our organization to engage with our community around OA, and to achieve our goals related to open scholarship.

As we wrestled with this conflict and emotion, we recognized that we as a library cannot practice according to our values if we do not know what our values are. We confronted head-on our assumption that our organizational values were clear-cut and in stark contrast to users' needs, which was preventing our ability to respond to Elsevier's acquisition of bepress. To make an informed decision in the face of the Elsevier acquisition, we needed to provide space for all staff perspectives related to OA to be heard. Only by doing so could we begin to collectively shape an understanding of and strategy for OA. In reality, our values were more nuanced than we had initially anticipated, which is something we only came to realize after providing staff with a space to articulate their perspectives. Throughout this process, we challenged the notion that our organizational policies and practices are an accurate reflection of the values of the entire staff complement. By turning the lens that we use to understand the needs of our users on ourselves, 
we were able to unpack our individual values and create a meaningful, grassroots policy statement on OA.

\section{Institutional Context}

Western Libraries is one of the top ten research libraries in Canada, encompassing eight service locations distributed across the University of Western Ontario campus. It is also a member of the Ontario Council of University Libraries, the Canadian Association of Research Libraries, and the Association of Research Libraries. The size and scope of Western Libraries' collection is in keeping with that of a research-intensive university, with access to an impressive array of collections and content (including OA content made available through numerous publishers and organizations) to support students and faculty across thirteen faculties and nearly one hundred departments. Western Libraries' collections and services are further enhanced through its collaborative relationship with three affiliated university college libraries: Brescia University College, Huron University College, and King's University College.

For over a decade Western Libraries operated under a liaison model with librarians and archivists providing research, instruction, and collections support for one or more campus departments. In June 2017, following many months of staff consultation and planning, the library administration proposed its new Organizational Renewal Initiative in which library services are built around five core functional areas: User Experience \& Student Engagement; Teaching and Learning; Research and Scholarly Communication; Content Management, Discovery, and Access; and Archives and Special Collections. The new emphasis on Research and Scholarly Communication necessarily shifted the work associated with OA from a committee related mandate to the individual core responsibilities of team members, which in turn necessitated a critical conversation about why and how we value and support OA.

Concomitant with the organizational renewal was the library's decision to discontinue its OA Fund which existed to support authors wishing to publish articles in OA journals that charge article processing charges (APCs). There was consensus that the OA Fund was not an efficient model to support OA in a broad way. The fund only supported the publication of a few papers, most of which were published by large for-profit publishers. Spending that same amount on institutional memberships or similar initiatives that support OA publishing and open infrastructure would allow us to support more authors on campus, or to explore alternative funding and OA publishing models. This decision gestured toward a more values-based approach to supporting OA; however, any values underpinning the rationale were not made explicit.

This is not to say that Western Libraries did not value OA prior to the reorganization; quite the contrary. Our approach to supporting OA (and scholarly communication work in general), however, tended to be risk-averse and conservative, focused on the how of OA rather than the why. Public facing messaging about OA was centred on meeting compliance-based mandates 
such as those established by the Tri-Agency ${ }^{1}$ and other grant funding bodies, with very little emphasis placed on the values of OA. Support for researchers was reactionary and scatter-shot due to the reality that knowledge and expertise for OA was concentrated in one or two individuals who were doing this work on top of other full time responsibilities. The organizational renewal provided a mechanism for knowledge transfer that would facilitate a more distributed, coordinated, and intentional approach to OA support.

Another example of Western Libraries' early efforts to support OA is our long and fruitful relationship with bepress. Since 2009, bepress has been used to power our institutional repository, Scholarship@Western, which collects, disseminates, archives, and preserves a variety of materials created or sponsored by the University of Western Ontario. In December 2017, Scholarship@Western achieved a milestone with its five millionth download, and as of June 14, 2018 there were 24,564 works posted and 5,825,028 downloads. Much of our support for OA centred on the benefits of using the institutional repository, making the mechanics of OA a focal point. It was Elsevier's unanticipated acquisition of bepress that provided a tipping point for a system-wide conversation about OA.

\section{Literature Review}

Our approach to unfurling and reconstituting our understanding of and support for OA was informed by the coalescing of three factors.

\section{Community Response to bepress Acquisition}

With the renewed focus on building capacity to support OA work in our local context, the acquisition of bepress by Elsevier shocked our campus community. We were not alone. Educational institutions across North America reacted adversely to the surprise announcement. On the day bepress announced this acquisition, individual reactions ranged from fear to rage to disappointment. As bepress customers were not consulted with or notified before the public announcement, emotions ran high (Schonfeld, 2017a) ${ }^{2}$. Within hours, librarians and scholars were calling for the identification and/or development of alternative solutions (O'Keefe, 2017). In the days following, organizations began to take action. The Public Knowledge Project (PKP) released a statement targeted at bepress users who publish original content through the Digital Commons journal-hosting platform. This statement not only detailed the potential benefits of using PKP's Open Journal System, but also announced the development of a migration plugin specifically designed to move content away from Digital Commons (Stranack, 2017). Within and outside of the academic library community, tensions related to the acquisition remained high for several months; within one month, the Scholarly Publishing and Academic Resources Coalition

\section{${ }^{1}$ The Canadian Institutes of Health Research (CIHR), the Natural Sciences and Engineering Research Council of Canada (NSERC), and the Social Sciences and Humanities Research Council of Canada (SSHRC) http://science.gc.ca/eic/site/063.nsf/eng/h_97415.html}

${ }^{2}$ Note: This knowledge comes from both Schonfeld's piece and our own personal knowledge as bepress customers. 
(SPARC) issued a direct and public statement detailing their disappointment at Elsevier's business practices that are antithetical and incompatible with OA work:

The acquisition is especially troubling for the hundreds of institutions that use Digital Commons to support their open access repositories. These institutions now find their repository services owned and managed by Elsevier, a company well known for its obstruction of open access and repositories (Joseph \& Shearer, 2017).

This discontent turned into action on the part of many libraries. Most notably, the University of Pennsylvania issued a statement about their intentions to leave bepress because of the acquisition in November 2017. They called this plan "Operation beprexit." They approached their intended migration with an emphasis on clearly articulating why they support an institutional repository and what types of supports or services those values might spawn (Allen, Wipperman \& Whitebloom, 2017). They concluded their statement with a call to action to the academic community to "...find solutions that align with our values as researchers, libraries, and universities and serve our collective communities' needs” (Leaven, 2017).

\section{Values-based practice}

The values of librarianship, institutional values (both at the university and library-level), and the values of individual library workers have often been invoked as the tides of practice change. Historically, library research has tended to focus on demonstrating library value to external stakeholders as opposed to understanding library values (Drabinski \& Walter, 2016). The library community is experiencing an internal conflict as we struggle to both be a "neutral" space welcome to anyone, while we also attempt to work in a socially conscious way, imposing our values and using our "neutral" position within the community to be anything but apolitical (Lewis, 2008; Sendaula, 2017; Weissinger, 2003). At the same time, we have begun to reflect more critically on our practice, evaluating the ways we have portrayed ourselves as neutral while still acting in ways that demonstrate our privilege (Christen, 2017).

In the business world, values-based practice is defined as "... doing the right thing for the right reasons and not compromising core principles” (Dean, 2008). There is an enormous body of literature on the positive impact of values-based leadership on stewarding a successful business career, a better workplace culture, and a more profitable corporation. However, in librarianship, the term "values-based" tends to refer to a set of core values as articulated by an organization or professional society. Most notably, the American Library Association's Core Values of Librarianship document is used as the backbone of many articles on values-based practice in libraries (Miller, 2007). These values, however, were not sourced by the library community at large; rather, they were initially created by a small task force. Each member of the task force was asked to identify values they felt were of universal importance across all libraries. Over one hundred values were proposed, and the task force whittled these one hundred down to eight (Weissinger, 2003). Individual subfields of librarianship have issued calls for a need to define a statement of core values to facilitate improved collaboration and goal-setting in a 
nebulous or rapidly changing field (Spiro, 2012; Ferguson \& Bunge, 1997). However, in more recent calls for values-statements, there is an acknowledgement that statements of shared values can limit growth and experimental work that pushes the boundaries of these values. As such, Spiro recommends that these values-statements be created with significant community contribution, in order to build consensus around the final product (Spiro, 2012).

\section{Design Thinking and Consensus Building}

The rise of User Experience and Design Thinking methodologies in libraries has provided a framework with which to build consensus around service and space design. Its most popular applications have been in rethinking library spaces beyond the carrel and rethinking the library's presence online. Typical applications involve direct consultation with or observation of users (Grguric, Rigling, Waller \& Cross, 2017). However, it is important to establish a common understanding of organizational goals and strategies before taking on a human-centered design project. Only by beginning with an internal focus can a library align user needs with an organization's priorities and mission (Heath, 2016). Design thinking has also proved to be an effective way to parse together disparate concepts and identify common themes and connections to create effective policies that account for obstacles (Mintrom \& Luetjens, 2016). By creating a concept map of a problem space, one is able to both broadly identify the range of ideas associated with the space and to also narrow down these ideas to start forming consensus and identifying meaningful patterns (Knudtson, 2016).

\section{Our Approach}

As members of the Scholarly Communications Subcommittee at Western Libraries, we each had a vested interest in supporting "open" on campus and had volunteered our time to committee work. Our project team was comprised of Emily Carlisle, a co-op student from the Faculty of Information and Media Studies working on special projects related to journal hosting and the institutional repository, Courtney Waugh, a liaison librarian with research interests in critical librarianship and an emerging professional focus in scholarly communication, and Lillian Rigling, a recent librarian hire and the newly appointed co-chair of the Scholarly Communications Subcommittee with a background in user experience design work. Each of us brought a unique perspective to this problem space, but we shared the common goal of rethinking OA work.

Hoping to establish a common understanding of organizational values around OA - with which we could begin to collectively shape an OA strategy that effectively serves our users-we employed an iterative design thinking process and design thinking strategies, specifically concept mapping. We approached this as an exploratory project, generating buy-in first from the Scholarly Communications Subcommittee. On behalf of the Scholarly Communications Subcommittee, we invited participants from across Western Libraries and our affiliate libraries to explore how we define OA, and why and how our libraries support it. Held on October 23, 2017 (and coinciding with the first day of Open Access Week 2017), our collaborative discussion brought nineteen participants from five different campus libraries, who together represented a 
range of job titles and levels of seniority. Student assistants, library assistants, and librarians were in attendance, coming from, for example, library information resources management, our map and data centre, our business library, and our Faculty of Information and Media Studies Graduate Library that supports the ALA-accredited MLIS program.

Following a discussion of OA in general, each attendee was asked to consider their opinion in response to the following prompts:

- What is open access?

- Why does (or should) Western Libraries support open access?

- How does (or could) Western Libraries support open access?

Participants were encouraged to independently write as many ideas as possible on individual sticky notes. After recording their responses on sticky notes, attendees worked in three groups to collaboratively generate concept maps out of the individual responses to each prompt. Similar responses were grouped together under encompassing terms, while relationships between each of the grouped concepts were captured and articulated.

All three groups were given an opportunity to rework each of the concept maps. Each group spent a few minutes interpreting the concept map and making changes as they saw different or missing connections or ideas. The groups then presented back to all in attendance, and a discussion was held in order to ensure that the ideas and relationships captured in the final versions (pictured below) reflected group consensus. The three concept maps together illustrate each attendee's individual understandings of $O A$, made meaningful by a visual structure that represents the group's understandings of OA. 


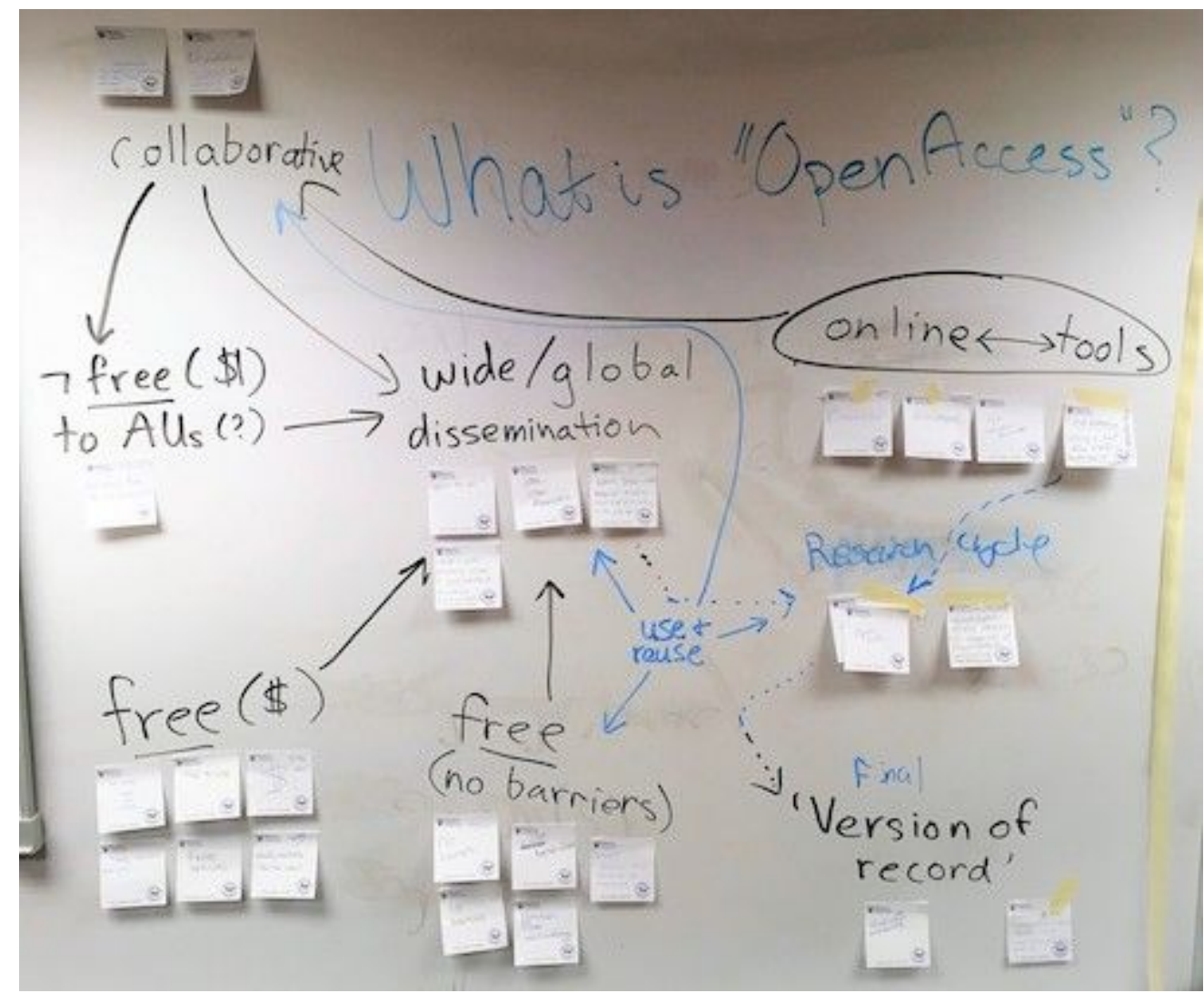

Figure 1: Finalized concept map formed in response to the prompt, "What is open access?"

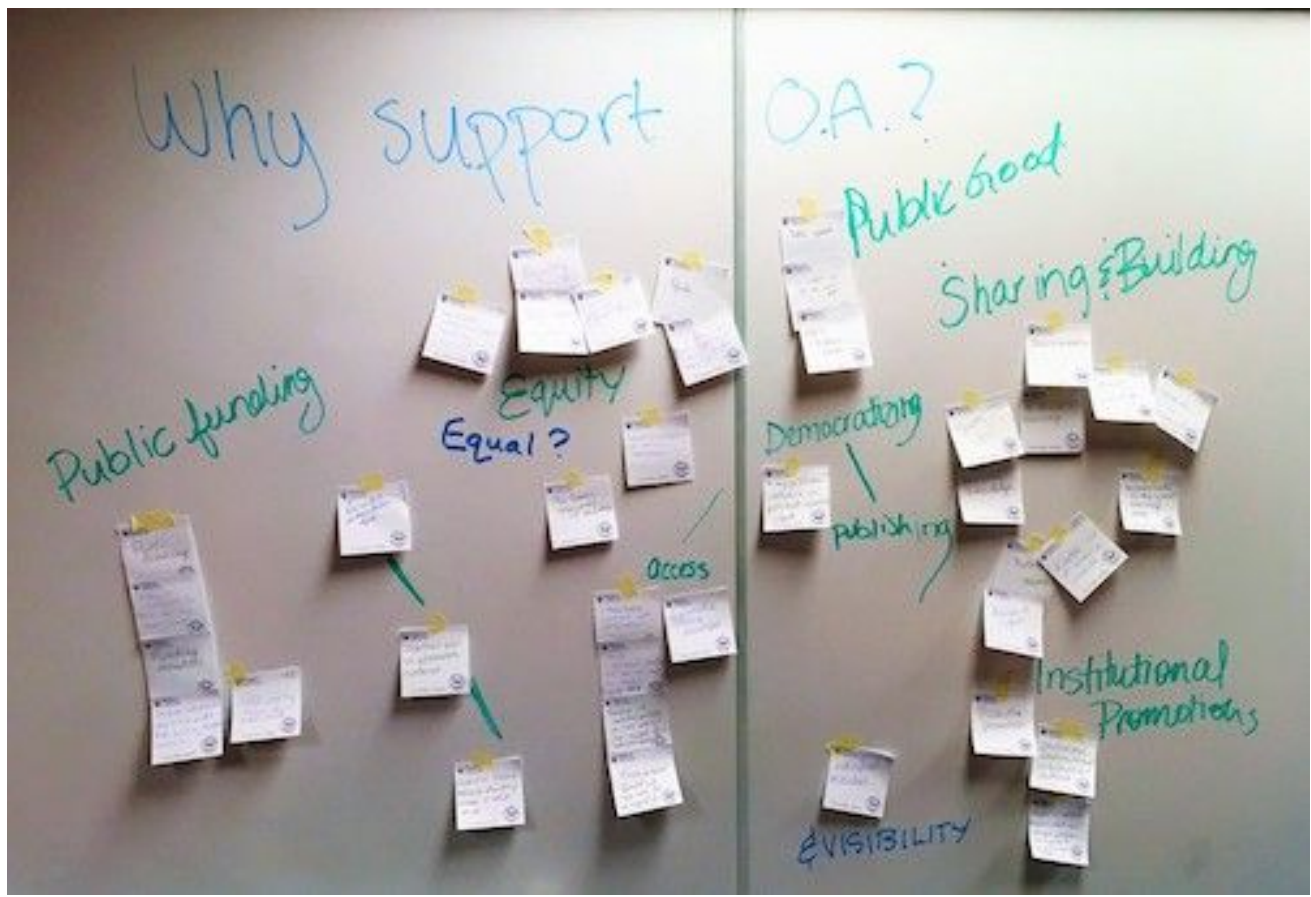

Figure 2: Finalized concept map formed in response to the prompt, "Why does (or should) Western Libraries support open access? 


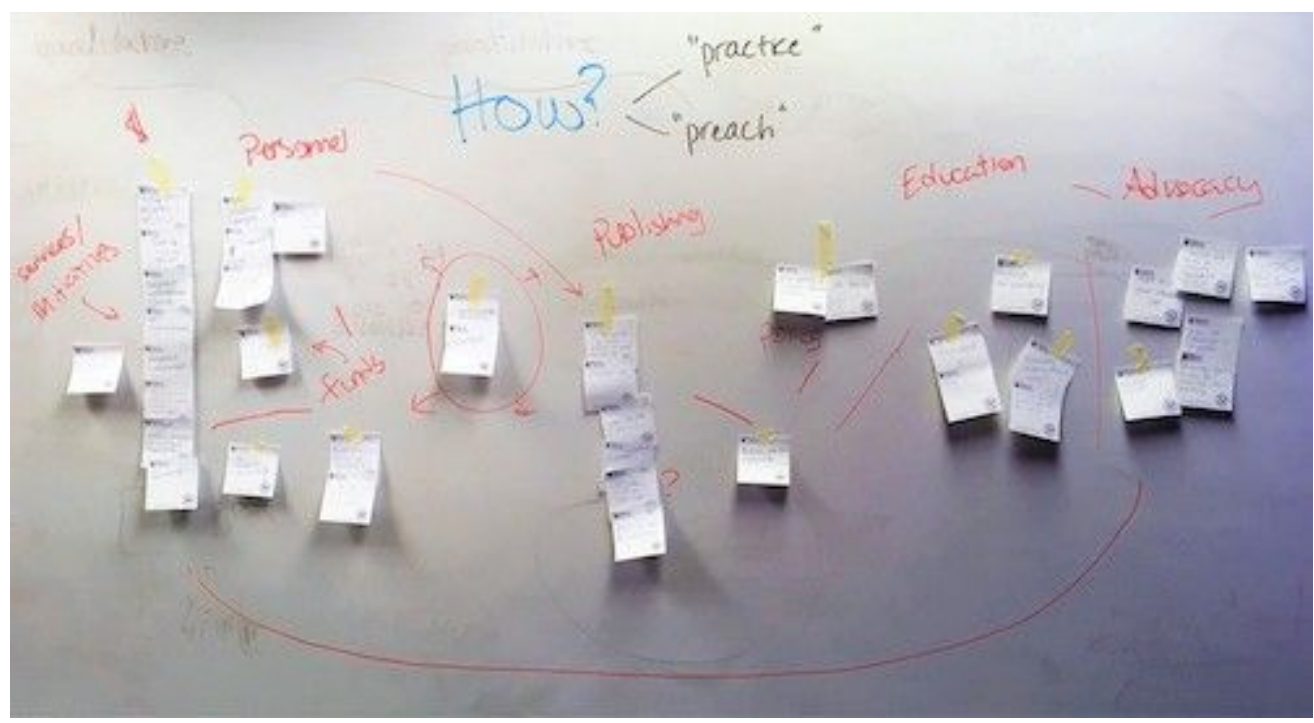

Figure 3: Finalized concept map formed in response to the prompt, "How does (or could) Western Libraries support open access?"

We also attempted to address any gaps in the concept maps by having a broader, open-ended discussion about how we currently present OA to our community and how other similar institutions present OA. We provided anonymized OA statements from several university libraries and had participants write down as individuals what they thought worked well and what could be improved. We then had an open-ended conversation about these statements and what potential qualities would improve the efficacy and comprehensiveness of Western Libraries' statement. Finally, we distributed an anonymous survey to assess the event for individuals who had attended, and to provide an opportunity for individuals who were unable to attend to offer feedback on the three questions we posed for the concept maps as well as on the general topic of Western's OA statement.

\section{A New Statement}

These concept maps, the virtual participation, and the artifacts of the discussion were used to inform Western Libraries' new statement on OA. Courtney Waugh, who had been involved in the session planning but was not present during the collaborative event, brought a fresh perspective that was helpful for analyzing and synthesizing the data. Drawing on the concept map visuals and the sticky notes produced by each attendee, she identified central themes that best captured how Western Libraries defines OA, and why and how our Libraries support it. Central themes were determined from recurring terms in individuals' sticky notes, and from the differentiated groups that brought together related ideas in the concept maps. These themes, coupled with attendees' suggestions for improving the existing OA statement (pictured below), were then incorporated into a new and improved OA statement. 


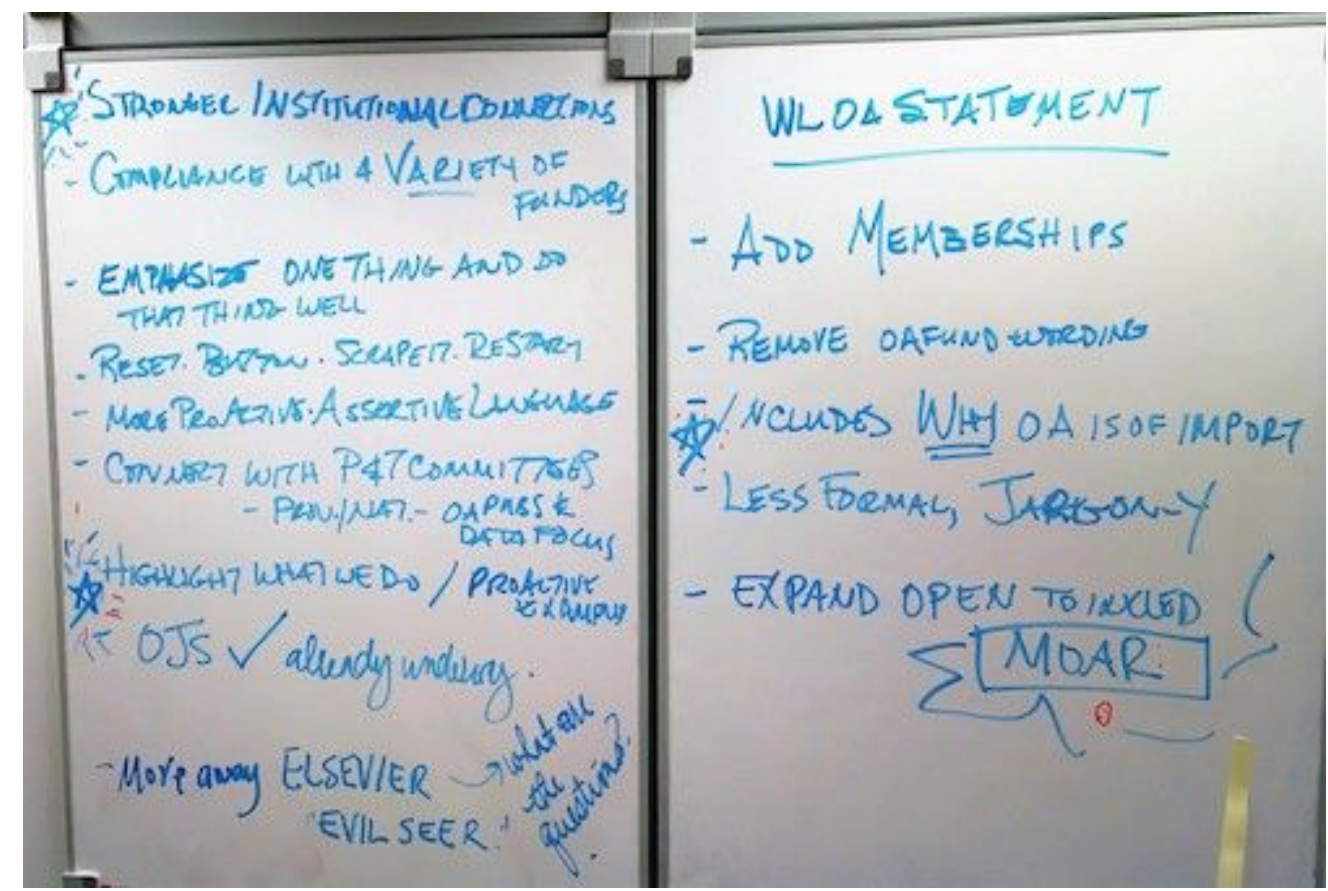

Figure 4: Identified areas for improvement in our old open access statement.

The new statement takes a more proactive position on OA, highlighting Western Libraries' commitment to key values embedded in OA such as equitable access, innovation in research, and the sharing and reuse of new ideas. The statement also describes how Western Libraries partners with researchers looking to pursue open avenues, highlighting services such as individual consultations, education via outreach and workshops, self-archiving support, institutional memberships, and journal publishing. Additionally, the statement recognizes that in an evolving scholarly ecosystem, "experimentation is necessary in order for libraries, publishers, and our communities to find sustainable models for open research." As such, the statement is flexible, subject to change as Western Libraries' commitment to OA is embodied in new or adapted services.

More importantly, the new statement reflects understandings of OA across different roles and levels in our library system. Throughout Western Libraries, staff in different roles and departments have developed understandings of OA that are rooted in their personal experiences and interactions with Western's community. Considering these understandings and experiences during the process of developing the new statement has allowed for the creation of a statement that captures values and services related to OA in their most relevant sense to Western Libraries' staff and community.

Perhaps because of the new statement's reflection of staff values within and across Western Libraries, the initial draft made its way to senior leadership with little objection. The approval of leadership was crucial for us in a time of transition, but because of the enormous amount of change happening within the organization at the time of this project, we anticipated our project might be subject to backlog. Additionally, because of the grassroots nature of this project, we 
were unsure of how it would be received; we had not sought administrative approval to write a new OA statement. However, given the significant artifacts of our process, and the transparency in our consultation, the leadership was prepared to receive the statement and our wait for approval was short.

We presented the new statement to members of our Ontario library consortium at the Ontario Library Association Super Conference in 2018 and received a similarly positive response. Since its official implementation in January 2018, the new OA statement has provided a solid foundation on which to make thoughtful decisions about Western Libraries' support for OA. It has inspired the pursuit of initiatives that align with our communal values; for example, investment in institutional memberships to OA initiatives or open infrastructure and active investigation of open educational resources. In the coming months the statement is also set to inform a campus-wide OA policy-a move that aligns with the value that Western Libraries places on having the campus community recognize OA as a priority. Built out of a focus on building consensus around values and service, the new statement is proving an effective means of pursuing actions that are rooted in our organizational values.

\section{Implications for library policy development}

Throughout this process, we recognized that this strategy was not only an effective way to create meaningful change with a new statement, but also that the process itself disrupted organizational norms around policy creation and empowered new voices to be represented in library policy. By inviting participation from casual and part-time employees, students, and library assistants, we heard different and valuable perspectives. Additionally, by creating an environment where non-administrators represented the overwhelming majority of participants and all participants had an opportunity to contribute their individual ideas without attaching their identity or position, we did our best to disrupt organizational power structures at play in a typical committee. By continuing this strategy for our work, we may over time be able to increase participation from library assistants, student staff, and non-managers in articulating the creation of organizational values and culture.

The artifacts we produced from this event, including photos, sticky notes, and virtual feedback, provided strong documentation to support the choices we made in synthesizing the data. For example, when a question was posed after the release of the statement about the choice of the term "equitable access" as opposed to "equal access," we were able to point specifically to the place on the "Why support open access" concept map where equity and equality were discussed, and elaborate on that discussion. These artifacts will also prove helpful with generating administrative buy-in as we move forward in scaling our approach to create a campus-level OA statement.

\section{Conclusion}

Libraries are having more crucial conversations about neutrality, and are working to strike a balance of service-oriented and social-justice-oriented work. We have been broadly interpreting 
our post-Enlightenment era value of "access to information" to strive for a nuanced and intricate understanding of equity within information access. However, in order to continue aligning our practices with our values, it is important that we not only articulate the values of the profession, but also explore our personal values. As facilitators, we were challenged to articulate our own understanding of open and work to incorporate our conceptions with those of our colleagues. What we would have approached as wordsmithing and editorial work in a committee-setting, we saw instead as an opportunity for personal exploration. The process was also liberating for us as Western Libraries staff. By clearly articulating our commitment to OA services as a way to contribute to equity of the global knowledge base, we were able to reimagine conversations with our local community and make room for experimentation with new ideas. It also allowed us to say no to projects and partnerships that didn't share our values. For example, when asked to support a membership with a publisher to support Article Processing Charges for hybrid journals, we were able to clearly refer to our statement and only support "publishers or organizations that develop and advance open infrastructure." Finally, by making the process inclusive of any staff member who indicated interest, it began to open the doors for new conversations between staff. We have been able to strike project teams that are inclusive of staff and librarians who do not have job titles or job description that mention "open" but who bring a unique perspective and passion to the table.

By practicing librarianship through the exploration of our own values, we can develop meaningful and actionable policy and service. Turned on ourselves, design thinking is a powerful means to identify individual and organizational values and to develop policies out of communal values. With this basis we can then begin an external approach, aligning our users' needs with the mission and values that are prioritized across our organizations or profession as a whole.

\section{Acknowledgements}

We are so thankful for the support of our colleagues at Western Libraries in this process: the individuals who brought energy and critical perspectives to our event, Vice-Provost and Chief Librarian Catherine Steeves who supported the dissemination of this statement, and Joanne Paterson who helped facilitate our concept-mapping event. Thanks also to our colleague Kristin Hoffmann for copy-editing to improve the clarity of our writing. We express gratitude to our peer reviewers, Donna Lanclos and Annie Pho, for your support and ideas, and to Sofia Leung, our publishing editor, for keeping us on track. Finally, we are especially grateful for the wonders of WiFi on busses and planes, allowing us to work on this from literally anywhere in the world.

\section{References}

Allen, L., Wipperman, S. L., \& Whitebloom, K. (2017). Beprexit: Rethinking repository services in a changing scholarly communication landscape. In CNI Fall 2017 Membership Meeting. Retrieved from https://repository.upenn.edu/library_papers/106 
Carlisle, E., Rigling, L., Paterson, J., \& Waugh, C. (2018). Open by default? Concept mapping our way to open access consensus. Presented at the Ontario Library Association Super Conference.

Christen, K. (2017). We have never been neutral: Search, discovery, and the politics of access. Lecture presented at Distinguished Speaker Series, Dublin, Ohio. Retrieved from https://www.oclc.org/research/events/2017/07-13.html

Dean, K. W. (2008). Values-based leadership: How our personal values impact the workplace. The Journal of Values-Based Leadership, 1(1).

Drabinski, E., \& Walter, S. (2016). Asking Questions that Matter. College \& Research Libraries, 77(3), 254-268. doi: 10.5860/crl.77.3.264

Ferguson, C. D., \& Bunge, C. A. (1997). The shape of services to come: Values-based reference service for the largely digital Library. College \& Research Libraries, 58(3), 252-265. doi:10.5860/crl.58.3.252

Grguric, E., Rigling, L., Waller, M, \& Cross, W. (2017). Applying design thinking to the scholarly communications problem space. Presented at the Force11 Scholarly Communications Institute.

Heath, P. (2016). Applying human-centered design to the library experience. In A. Priestner \& M. Borg (Eds.), User experience in libraries: Applying ethnography and human-centered design(pp. 49-67). New York, NY: Routledge.

Joseph, H., \& Shearer, K. (2017, September 06). Elsevier acquisition highlights the need for community-based scholarly communication infrastructure. Retrieved from https://sparcopen.org/news/2017/elsevier-acquisition-highlights-the-need-for-community-b ased-scholarly-communication-infrastructure/

Knudtson, E. (2016, August 30). Concept mapping for designers of the future. Retrieved from https://www.cooper.com/journal/2016/8/concept-mapping-for-designers-of-the-future

Leavens, S. (2017, October 9). Penn Libraries to end partnership with bepress. Retrieved from https://beprexit.wordpress.com/official-statement/

Lewis, A. (2008). Introduction. In A. Lewis (Ed.), Questioning Library Neutrality: Essays from Progressive Librarian. Library Juice Press.

Miller, R. K. (2007). The value of values-based literature: An exploration of librarianship's professional discussion of core values (Unpublished master's thesis). University of North Carolina, Chapel Hill. 
Mintrom, M., \& Luetjens, J. (2016). Design thinking in policymaking processes: Opportunities and challenges. Australian Journal of Public Administration, 75(3), 391-402.

doi:10.1111/1467-8500.12211

Naqvi, R. (2018, January 25). Western research repository reaches five millionth download. Western Gazette. Retrieved from https://www.westerngazette.ca/news/western-research-repository-reaches-million-downlo ads/article_f3f3f430-01f3-11e8-aee6-f3eca4329a33.html

O'Keefe, K. (2017, August 3). Elsevier acquires bepress: Library and knowledge community respond [Web log post]. Retrieved from https://kevin.lexblog.com/2017/08/03/elsevier-acquires-bepress-library-knowledge-commu nity-respond/

Schonfeld, R. C. (2017a, August 02). Elsevier acquires institutional repository provider bepress. Retrieved from https://scholarlykitchen.sspnet.org/2017/08/02/elsevier-acquires-bepress/

Schonfeld, R.C. (2017b, August 07). Reflections on "Elsevier acquires bepress." Ithaka S+R. Retrieved from http://www.sr.ithaka.org/blog/reflections-on-elsevier-acquires-bepress/

Sendaula, S. (2017, July 07). Libraries are not neutral spaces: Social justice advocacy in librarianship. Retrieved from https://lj.libraryjournal.com/2017/07/shows-events/ala/libraries-are-not-neutral-spaces-alaannual-2017/

Spiro, L. (2012). "This is why we fight": Defining the values of the digital humanities. In M. K. Gold (Ed.), Debates in the Digital Humanities. University of Minnesota Press.

Stranack, K. (2017, August 8). Rethinking bepress [Web log post]. Retrieved from https://pkp.sfu.ca/2017/08/08/rethinking-bepress/

Weissinger, T. (2003). Competing models of librarianship: Do core values make a difference? The Journal of Academic Librarianship, 29(1), 32-39. doi:10.1016/s0099-1333(02)00403-2

Western Libraries. (2018). Open access. Retrieved from https://www.lib.uwo.ca/scholarship/index.html 
Published July 15, 2018, In the Library with the Lead Pipe, http://www.inthelibrarywiththeleadpipe.org/2018/oa-statement/

(c) (†)

This work is licensed under a $\underline{\text { CC Attribution } 4.0 \text { License. }}$ 